\title{
República Dominicana: a construção do pueblo criollo
}

\author{
Renata de Melo Rosa'
}

\section{Resumo}

Este artigo explora os limites do nacionalismo dominicano que, ao se opor binariamente ao nacionalismo haitiano, constitui-se em uma alteridade perfeita que, mesmo assim, não consegue ocultar o princípio de transitabilidade existente na constituição de identidades nacionais opostas. Dessa forma, é a partir do trânsito contínuo pela identidade haitiana que o nacionalismo dominicano irá construir seus principais pilares, parecendo perder o seu significado, caso essa oposição não seja continuamente reproduzida pelo pensamento social e pela historiografia dominicana. Alguns fatos históricos foram extremamente importantes para alimentar o nacionalismo dominicano que se converte em antihaitianismo. São eles as invasões haitianas a Santo Domingo em 1801, 1804 e 1822 (a mais duradoura). O fato de os dominicanos haverem sido dominados por uma nação que era ela mesma fruto de uma insurreição escravista fez com que, em grande parte do pensamento social dominicano, a repulsa aos haitianos não se restringe apenas ao povo, mas à idéia de negritude, religião e culturas de matriz africana.

Palavras-chave: Antihaitianismo. Pensamento social dominicano. Nacionalismo Dominicano. Invasões Haitianas.

\section{Introdução}

Este artigo tem como objetivo apresentar, por meio do pensamento social dominicano, os valores que dão suporte à construção do nacionalismo dominicano. Para esse fim, tomarei como foco de análise a literatura que trata das ocupações haitianas de 1801, 1805 e 1822 a Santo Domingo ${ }^{2}$, por perceber que

${ }^{1}$ Coordenadora do curso de Relações Internacionais do UniCEUB.

${ }^{2}$ Santo Domingo, em itálico, será o termo designado aqui para falar do período colonial da parte espanhola da ilha. 
esses momentos constituem elementos cruciais de construção da oposição binária constitutiva desse nacionalismo.

É necessário ressaltar que, antes dessas ocupações, o esboço do que posteriormente veio a se configurar como valor substancial da oposição binária com o nacionalismo haitiano, centrado no valor da pureza, já figurava nas narrativas de diversos viajantes, por meio da observação do valor da mezcla como formadora de um povo cristão e pacífico que encontrou na tradição hispânica seu principal fundamento moral. Essa percepção compõe as observações de Moreau de Saint-Méry, político francês, em visita a esta região em 1783:

Los prejuicios de color, tan poderosos en otras naciones, donde se ha establecido una barrera entre los blancos y los libertos o sus descendientes, casi no existen en la parte española. Por eso, las leyes de las Indias españolas sobre los libertos han caído absolutamente en desuso [...] es también rigurosamente cierto que la gran mayoría de los colonos españoles son mestizos, que tienen todavía más de un rasgo africano que los traicionan luego, pero que han hecho disimular un prejuicio que podría considerarse nulo [...]

Resulta deesta opinión unfavor quese extiende necesariamente a los esclavos. Estos son alimentados, en general, como sus amos, y tratados con una dulzura desconocida en los otros pueblos que poseen colônias. Por otra parte, (como) todo esclavo puede hacerse libre, pagándole el precio al amo, quien no puede negarse (a aceptarlo), es muy natural que la idea de verlos pasar a cada instante a la clase libre, impida tratarlos con esta superioridad que existe ordinariamente entre amo y esclavo. Así, pues, la servidumbre se encuentra muy moderada, de una parte por la esperanza de hacerla cesar $y$ de otra, por la costumbre de confundirse, en cierto modo, con aquellos que poco antes eran todavía esclavos (SAINTMÉRY, 1944, p. 92-95).

O pensamento de Delafosse (1946) também expressa a mezcla como um dos principais pilares do nacionalismo dominicano. Apesar de reconhecer que a diversidade de cor caracteriza a formação desse povo, o autor observa que tais diferenças não são utilizadas como um modelo objetivo de organização social para a separação e atribuição de direitos diferenciados. Pelo contrário, a despeito das diferenças, existe uma unidade criolla, a qual, é capaz de responder pela diversidade de cores e tradições culturais. 
! Blanco, amarillo, cobrizo, o negro, (el mestizo o el negro dominicano) es un español que está orgulloso de sí mismo! Desgraciado de aquel que se atreva a darle su verdadera denominación, pues entonces la cólera reemplaza a la paciencia y aunque sea negro como el ébano, os contestará golpeándose el pecho con orgullo, más grande todavía en Indias Occidentales que en Europa mismo: iyo, soy yo, blanco de la tierra! Porque él había nacido criollo y no africano (DELAFOSSE, 1946, p. 151).

A narrativa acerca da formação do povo dominicano o concebe como o avesso do povo haitiano. Na literatura dominicana, os criollos ocupam um papel simbólico de extrema importância e participam da retórica nacional no sentido da construção de uma nação imaginada que seleciona, tal como a haitiana, os elementos desejados para a articulação de seu nacionalismo ${ }^{3}$. A análise da relação dos valores que dão sentido ao nacionalismo dominicano será trabalhada neste artigo a partir do significado produzido pelas ocupações haitianas de 1801, 1805 e 1822 . Tais ocupações foram classificadas por Marrero ${ }^{4}$ como "una era de desmedidas ambiciones de los antiguos esclavos de la parte occidental en relación con el territorio y el pueblo español-dominicano" (MARRERO ARISTY, 1957, p. 187).

A partir de 1801, a parte espanhola da ilha, Santo Domingo, sofreu diversas invasões por parte dos chefes de Estado haitianos: Toussaint L' Ouvertoure, em 1801, Jacques Dessalines, em 1805, e Jean Pierre Boyer, em 1822. De acordo com os relatos recolhidos por Rodríguez Demorizi ${ }^{5}$, tais ocupações foram extremamente violentas e serviram para marcar os valores diferenciados relativos ao povo dominicano e haitiano. Em grande parte da literatura dominicana ${ }^{6}$, os soldados haitianos estão

${ }^{3}$ Cf. ANDERSON, Benedict. Nação e consciência nacional. São Paulo: Ática, 1989. Tradução de: Imagined communities: reflections on the origin and spread of nationalism; HOBSBAWN, Eric. Nações e nacionalismos desde 1780. Rio de Janeiro: Paz e Terra, 1991.

${ }^{4}$ Cf. MARRERO ARISTY, Ramón. República Dominicana: origen y destino del pueblo cristiano más antiguo de la América. Ciudad Trujillo: Del Caribe, 1957.

${ }^{5}$ Cf. RODRÍGUEZ DEMORIZI, Emilio (Ed.). Invasiones Haitianas de 1801, 1805 y 1822. Ciudad Trujillo: Academia Dominicana de la Historia, 1955.

${ }^{6}$ Convém ressaltar que a literatura norte-americana a respeito do Haiti também contribuiu, de maneira relevante, para a atribuição da selvageria ao povo haitiano. Muitos dos historiadores dominicanos legitimam esta percepção, a partir das obras de origem norteamericana, como veremos em seguida. 
representados como animais selvagens ${ }^{7}$, pois não teriam incorporado os valores provenientes da civilização, como tampouco o teria feito o próprio povo haitiano. A causa para a permanência desse povo no estágio de selvageria seria a separação radical que o modelo colonial francês, baseado no sistema de plantation, impusera a seus escravos. De modo diferente, a colonização espanhola, adotara um modelo de exploração econômica diverso. O tráfico de escravos para o Caribe Hispânico foi anterior à plantation, e os escravos ocuparam funções diversificadas, especialmente em Santo Domingo. Eram artesãos, empregados domésticos, pequenos agricultores. Enfim, tratava-se de uma espécie de "contingente de apoio" ao estabelecimento dos espanhóis na ilha. Mais tarde, Santo Domingo foi abandonada pelos espanhóis, que rumaram ao México e, quando o regime de plantation começou a assumir o pilar de grande parte das economias coloniais do Caribe e das Américas, os escravos dominicanos já haviam se estabelecido na estrutura econômica de Santo Domingo de maneira análoga aos pequenos colonos ${ }^{8}$.

Essa diferença nas trajetórias das nações haitiana e dominicana permitiu que a literatura acerca do período colonial concluísse que Santo Domingo se constituía em tipo de sociedade que tinha como hábito o contato entre senhores e escravos, o que ocasionou o surgimento da mezcla em grande escala. Dessa maneira, os dominicanos, caudatários dos valores civilizatórios ocidentais, estão representados como religiosos, dóceis e cordatos. De acordo com a literatura dominicana examinada, a autoatribuição do valor da noblesse, significa que, em seu conjunto de valores, os haitianos reverenciam sua pureza africana e, por conseguinte, encontram sentido na selvageria e na barbárie. Em contrapartida, adotar a mezcla como valor

\footnotetext{
${ }^{7}$ Cf. MARRERO ARISTY, Ramón. República Dominicana: origen y destino del pueblo cristiano más antiguo de la América. Ciudad Trujillo: Del Caribe, 1957; BALAGUER, Joaquín. La Isla al revés: Haití y el destino dominicano. Santo Domingo: Librería Dominicano, 1984; CHEZ CHECO, José. Ideário de Luperón (1839-1897). Santo Domingo: Taller, 1997; RODRÍGUEZ DEMORIZI, Emilio (Ed.). Invasiones haitianas de 1801, 1805 y 1822. Ciudad Trujillo: Academia Dominicana de la Historia, 1955; DELAFOSSE, Lemonier. Segunda campaña de Santo Domingo: guerra Domínico-Francesa de 1808. Santiago: Editorial El Diario, 1946; e, ARREDONDO Y PICHARDO, Gaspar. Memoria de mi salida de la Isla de Santo Domingo el 28 de abril de 1805. In: DEMORIZI, Emilio Rodríguez (Ed.). Invasiones haitianas de 1801, 1805 y 1822. Ciudad Trujillo: Academia Dominicana de la Historia, 1955.

${ }^{8}$ A esse respeito, consultar SILIÉ, Rubén. Población y esclavitud en Santo Domingo, en el Siglo XVIII. Revista Investigación y Ciencia, [S.l.], ano 1, n. 1, 1986; e, SILIÉ, Rubén. Esclavege et prejuge de coleur en Republique Dominicaine. Revue Franco-Haitienne, Conjonction, [S.l.], n. 147, 1980.
} 
referencial significa reconhecer as virtudes da tradição hispânica na sua formação e estar de acordo com os valores advindos da civilização europeia.

\section{As ocupações haitianas}

A ocupação de 1801 diz respeito aos intentos de Toussaint L'Ouverture no sentido de ampliar seu raio de ação política em toda a Hispaniola. Elevado ao posto de General pela monarquia francesa, L'Ouverture começa a traçar esta ocupação em 1800. Contudo, ela seria concretizada em 1801. Marrero descreve o início destas ocupações:

El quid de la tragedia dominicana se arraiga en el crecimiento desmedido del poder de Toussaint L'Ouvertoure, el antiguo cochero que, por su habilidad como General improvisado, su ascendiente entre los negros y su traición a la bandera española, se halló de momento en una posición clave en el lado francés, y comenzó a ser mimado por los débiles y entre sí divididos funcionarios que enviaron a la isla tanto la Convención Nacional como el Directorio [...] Así pues, nada podría evitar que se cumpliera el fatal sino que iba a envolver en tinieblas y a bañar en torrentes de sangre a toda la islã (MARRERO ARISTY' 1957, p. 187).

Antonio Chanlatte, general de Brigada e Comissário do governo francês em Santo Domingo escreveu um informe ao governo francês ${ }^{9}$ acerca da ação de L'Ouverture, por ocasião do aumento de seu desejo de expansão territorial rumo à conquista de Hispaniola, cuja consequência mais explícita seria o rompimento do Tratado de Basileia ${ }^{10}$, estabelecido entre França e Espanha. Eis algumas palavras contidas neste informe:

Que lo digan, o no; que lo confiesen o que lo nieguen, o por temor al General Toussaint crean que deben callar, ello es que los mulatos de las comarcas Del Norte y Del Oeste han sido asesinados con premeditación bien concertada; en una palabra: Toussaint ha sido para esos desgraciados lo que fue Carrier para los ciudadanos de Nantes. Esta guerra, este

\footnotetext{
9 Trata-se do seguinte informe "Al Gobierno Francés y a todos los amigos de la soberanía nacional y del orden”. Santo Domingo, 20 de Prairial, Año VIII (9 de junio de 1800). (Ed). Emilio Rodriguez Demorizi, La Era de Francia em Santo Domingo, Ciudad Trujillo: Academia Dominicana de la Historia, 1955 apud Marrero Aristy, 1957.

${ }^{10}$ Tratado firmado entre França e Espanha, no qual, a Espanha cede Santo Domingo à França.
} 
prejuicio dura aún y durará mientras los mulatos no sean destruidos, o sus verdugos no tengan medios para saciar su sed de sangre y de muerte, hasta no dejar en la colonia hombres de color que no sea su color. Muy bien saben ellos que los blancos sin los mulatos, son tan pocos, que no quedará uno quince minutos después de firmado el decreto de su expulsión ${ }^{11}$.

Marrero prossegue na caracterização dos planos de invasão de L'Ouverture à Santo Domingo:

Toussaint decidió rubricar el acto cumbre de su programa de dominio de la isla, valiéndose de una serie de subterfugios para alcanzar sus sueños de grandeza: decidió apoderarse de la parte española de la isla desconociendo el Tratado de Basileia y atribuyéndose funciones que Francia no habia encomendado ni aún a sus propios Agentes, y que jamás habría puesto en manos tan peligrosas y de lealtad tan dudosa.

La decisión de apoderarse de Santo Domingo era, por demás, una necesidad para el negro [...]. Toussaint ambicionaba apoderarse de los ganados (reses, caballos, mulos) de los hacendados y hateros de la parte española, y reclutar gente entre los esclavos - que él suponía animados de los mismos odios y ferocidad de los negros de la parte francesa (MARRERO ARISTY' 1957, p. 195).

De acordo com os documentos apresentados por Marrero, a ideia de expansão de L' Ouvertoure rumo a Santo Domingo foi veementemente vetada pelo Agente Roume, responsável pela administração colonial francesa em Saint-Domingue. A alegação de Roume era de que essa ação só seria proveitosa, caso se restringisse exclusivamente à pilhagem dessa região. Caso contrário, a anexação daria a SaintDomingue muito mais prejuízos econômicos do que propriamente lucros. Apesar da tensão entre Romue e L'Ouverture, a ocupação ocorre em 1801, descrita da seguinte forma por Marrero:

La desgracia, por tanto tiempo temida, enseñaba ahora sus amenazantes fauces y los horrores de la chusma negra desbordada sobre una población cristiana educada en tradiciones de paz y orden moral que ya tenían profundas raíces, se presentaban en la mente de todos con sus consiguientes horrores (MARRERO ARISTY'1957, p. 198).

\footnotetext{
${ }^{11}$ Cf. RODRÍGUEZ DEMORIZI, Emilio (Ed.). La era de Francia en Santo Domingo. Ciudad Trujillo: Academia Dominicana de la Historia, 1955.
} 
A principal marca da ocupação de L'Ouverture, em Santo Domingo, foi a Libertação dos Escravos. A narrativa de Marrero enfatiza que, apesar de esta se caracterizar como uma ação louvável, Santo Domingo não urgia dessa ação, pois, entre senhores e escravos, havia uma relação de cordialidade, quando não de sexualidade e afetividade:

Un suceso que llenó de pavor a los habitantes libres de Santo Domingo fué la orden de reunirse en la plaza de armas, dada por Toussaint para anunciarles la abolición de la esclavitud en forma tan teatral que todos temieron haber sido llamados para ser degollados. En esa ocasión el usurpador iba tocando desconsideradamente a cada señora con la punta de su bastón, preguntándoles en mal español, si eran francesas o españolas, ante lo cual se rebeló doña Dominga Núñez $z^{12}$, señorita de la mejor sociedad de la capital, protestando contra tan bruscos modales y poniendo con ello en peligro la vida de todos.

Los esclavos de la parte española, que desconocían los malos tratos, las marcas con hierro candente y la brutalidad con que habitualmente trataban muchos franceses a los negros de la parte occidental, recibieron fríamente la libertad que les daba el invasor, evidentemente en razón de que la gente de color de la parte oriental se consideró siempre como española o blanca de la tierra, es decir, diferente por el género de vida y por la asimilación de la religión y las costumbres europeas, de los sufridos esclavos que poseían los franceses (MARRERO ARISTY'1957, p. 202, grifo nosso).

Arredondo y Pichardo (1955) descreve a posição dos brancos frente ao governo de L'Ouverture em Santo Domingo:

En el tránsito de un Gobierno a otro [...] sufrimos los naturales toda clase de insultos, salvando los peligros que teníamos encima, de una gente que ya abatida por los blancos, no economizaba la bayoneta o el sable, donde quiera que fijaba la vista, mientras le quedaba el momento de hacer el mal, y tomar la venganza, a pesar de la vigilancia

12 Este episódio é retratado pelo romancista dominicano Gastón F. Deligne. O autor descreve a atitude de Dominga Núñez da seguinte maneira:

Sublevada, hermosa, fiera, Tinta en carmín: - !Insolente!

Exclama -, para españolas, iotros modales aprende!

Cf. GARCÍA, José Gabriel. Compendio de la historia de Santo Domingo. Santo Domingo: Imprenta de García Hermanos, 1892. p. 303-304. 
con que se les observaba, pues durante su gobierno fuimos vejados de todos modos y nivelados con nuestros mismos esclavos en el servicio de las armas, y en todos los actos públicos. En un baile que dieron para celebrar la entrada de Moyse, antes de la venida de la armada francesa, se me hizo la gran distinción por el bastonero de sacarme a bailar con una negrita esclava de mi casa, que era una de las señoritas principales del baile porque era bonita, y no tuvo otro título ni otro precio para ganar su libertad, que la entrada de los negros en el país con las armas de la violencia. Infinitas veces provocaron los oficiales de esta tropa, lances en que buscaban el movimiento más insignificante de un blanco para romper con un degüelo, con un incendio, o cualquiera otra maldad que les autorizase al pillaje y al saqueo, de [lo] que nos preservó la divina providencia, dándonos un sufrimiento y una prudencia sin la cual habríamos seguido la suerte de nuestros paisanos de la parte Sur, que por el resto de la isla andaban errantes, testificando con su miseria su desgracia, llorando este al padre, aquel a su hijo, unos a la esposa sacrificada brutalmente, y otros al inocente inmolado en la punta de una bayoneta, dónde se le esperaba después de tirarlo al aire.

No es fácil reducir a breves páginas la multitud de amarguras, sobresaltos y angustias, que tuvimos que experimentar en aquella espantosa crisis. Felizmente los de Santiago no vimos a Toussaint más que tres días, pues su partida fue violenta y secreta como lo tenía de costumbre [...] Como Toussaint, con su alta hipocresía cubría un alma infernal y un corazón de tigre que solo respiraba sangre, fuego y muerte, todos le temíamos, a pesar de sus protestas de seguridad y protección. (ARREDONDO Y PICHARDO, 1955; MARRERO ARISTY' 1957, p. 203-204).

Marrero articula, ao longo de sua obra, a relação entre os valores que dão unidade ao nacionalismo dominicano, elaborado por meio da repulsa ao conjunto de valores que dá sentido ao nacionalismo haitiano: o alto valor outorgado à pureza racial e o consequente entendimento de que é a raça e não a cultura que cria unidade entre os indivíduos. Dessa forma, o valor do povo dominicano é concebido em notável oposição ao valor do povo haitiano. Assim, mesmo a Libertação dos Escravos da parte espanhola, implementada por L'Ouverture, teve interpretação distinta da parte francesa porque, segundo Marrero, apesar de pertencerem à mesma raça, os escravos dominicanos filiavam-se à cultura local de forma a tornaremse distintos de alma e pensamento dos haitianos: 
[...] cualquiera que fuese el sentido de las disposiciones públicas adoptadas por Toussaint en la parte española, éstas les resultaron extrañas y repugnantes a los pobladores de dicho territorio, habiendo quedado identificados todos los dominicanos que han hecho historia sobre esa época en que ni aún los esclavos - con algunas pocas excepciones - se sintieron atraídos por las personas o el régimen de gobierno impuesto por el jefe de los negros occidentales ${ }^{13}$, cuyo pasado, atraso cultural y odios de raza no tenían ninguna similitud con los del grupo africano o de origen africano, que vivía cristianamente unido, mezclado e identificado con los españoles en la parte oriental de la isla (MARRERO ARISTY' 1957, p. 204).

Sánchez Valverde (1949, p. 169) aborda em Idea del Valor de la Isla Española, a eroticidade entre senhores e escravos. Valverde não possuía uma visão otimista a esse respeito, mas será a partir desse elemento, que Marrero irá inferir as seguintes observações:

Estas relaciones eran tanto más frecuentes y normales, si se toma en consideración que en el Santo Domingo español los amos eran generalmente pobres, trabajaban hombro con hombro con sus esclavos, y convivían con ellos en sus haciendas o en sus hatos.

En el disfrute de tal régimen de vida, ¿qué odio podían tener los esclavos españoles contra sus amos, los que, como bien observó uno de los tantos viajeros extranjeros que visitaron el país en aquellos tiempos, dormían tranquilamente al lado de aquellos? Y ¿cómo iban a poder comprender los esclavos de la parte francesa, maltratados tan brutalmente como lo fueron, y liberados luego en medio de una orgía de crímenes horrendos, las costumbres de los pacíficos pobladores de la colonia española? (MARRERO ARISTY 1957, p. 205).

Essa breve ocupação foi dissolvida pelo envio de tropas do Exército de Napoleão a Santo Domingo, em 1802, com o objetivo de destituir L'Ouverture do cargo de General e restabelecer a ordem colonial. Cientes da oportunidade do enfraquecimento de poder de L'Ouverture, muitos dominicanos aproveitaram a chegada das tropas napoleônicas para se insurgirem contra a ocupação haitiana (MARRERO ARISTY'1957, p. 207-215). Contudo, após três anos, Santo Domingo sofreu uma segunda invasão haitiana, dessa vez, sob o comando de Jacques Dessalines, então Imperador ${ }^{14}$ do recémliberto Haiti.

\footnotetext{
${ }^{13}$ Leia-se: Haiti. O autor se refere à parte ocidental da ilha de Hispaniola.

${ }^{14}$ Título conferido a Jacques Dessalines, após a Independência de 1804.
} 
A ideia de ocupação de Santo Domingo adquiriu novo fôlego por meio de Jacques Dessalines, pois o contexto político era totalmente diferenciado: SaintDomingue havia deixado de ser colônia francesa, as tropas francesas haviam sido derrotadas e o Haiti estava inserido na História das Américas como a Primeira República construída por ex-escravos. Influenciado por tais vitórias, Dessalines decidiu retomar os planos de L'Ouverture e invadiu Santo Domingo em 1805 . Vejamos o relato de Marrero a respeito desta invasão:

El 5 de febrero de 1805 comenzaron a afluir atropelladamente a la ciudad de Santo Domingo, centenares de españolesdominicanos de la región fronteriza sureña, que llegaban a la capital con sus mujeres, hijos y parte de sus ganados, huyendo de las hordas negras que se preparaban a pasar la frontera (DELAFOSSE, 1946).

Dessalines invadió la parte española once días después (16 de febrero de 1805) con dos ejércitos: uno dirigido personalmente por él, con el General mulato Péthión como jefe de ingenieros, por el Sur, y otro al mando del negro Cristóbal, por el Norte. Los dos ejércitos sumaban veintiún mil negros, entre los que se contaban muy pocos mulatos, pues el Emperador ${ }^{15}$ habia exterminado a casi toda la gente de ese color en repetidos degüelos en su país (MARRERO ARISTY 1957, p. 222).

O relato de Arredondo y Pichardo (1955, p. 157) sobre a invasão de 1805 à cidade de Santiago, antiga capital dominicana, também descreve os haitianos como feras indóceis à procura de sangue:

Como una furia del averno, degollando en mano, atropellando cuanto encontraban, y haciendo correr la sangre por todas las partes.

Figúrese cuál sería la consternación, el terror, el espanto, en que de momento cayó aquel vecindario, tan descuidado, a la vista de hechos semejantes. El tropel de las mujeres huyendo sin saber para dónde, ni por dónde. Los gritos de niños $y$ ancianos que salían de sus casa despavoridos. Los eclesiásticos confundidos en medio de los que le pedían el consuelo. Las madres, unas con sus hijos al hombro, otras tratando de salvar al enfermo, que desde el lecho de dolor clamaba por el amparo que no encontraba. Unas buscando el marido otras tratando de ocultarse debajo de los altares, o de los matorrales

\footnotetext{
${ }^{15} \mathrm{O}$ autor se refere a Jacques Dessalines, a quem foi dado o título de Imperador, após a Independência Haitiana.
} 
de la sabana, desde donde oían la voz tremenda de muerte y sangre, con el ruido de la pólvora y el acero con que ya estaban las calles cubiertas de cadáveres. Un pueblo, en fin, abrasado con todos los elementos de la desolación y del exterminio, bajo el poder absoluto de unos feroces para quienes la voz de perdón y de la misericordia era una blasfemia. Ya tenía tendido el cerco por todas sus avenidas, como una red para que en su centro nadie escapara de su mortífera venganza. ¡Cuántas desgracias! ¡Cuántas lágrimas que llorar! ¡Cuántos excesos de parte de aquellos antropófagos! La honestidad, el pudor, la decencia, todo estaba en la calle y en las plazas a las diez del día, y aún en los templos, a merced de la brutal concupiscencia que estremecía la naturaleza. Un pueblo tan religioso, tan dado al culto, tan pacífico, tan cumplido en la moral, convertido en pocos instantes en un cuadro de horrorosos atentados, donde se veía la violencia y la fuerza ejercitada con el mayor descaro sobre la inocencia de la juventud $[\ldots]$

Rodeados por la tropa negra, perecían cuantos venían de los campos a darnos auxilio ignorando el estado en que nos hallábamos. El resto ocupó el centro de la ciudad, a horas en que todavía, como día de carnestolendas, estaba nuestro cura en el altar celebrando, y la iglesia cuajada de gente esperando comulgar todos los que dentro se encontraban [...] Los bárbaros se dirigieron con las armas en las manos al templo, asesinando a roso y bellozo, como suele decirse, y nada los detuvo y como si estuvieran en un campo de batalla, hicieron una carnicería horrorosa manchando de sangre con mano sacrílega el suelo y los altares de la casa de Dios [...] De allí el que pudo escapó para caer después en manos de los caribes que recorrían la ciudad y no perdonaban vida al que encontraran.

En un abrir y cerrar de ojos se inundó la población de cadáveres y de sangre. Aquí, unos degollados, allí otros acribillados de balas. Más adelante otros dando vaivenes con las ansias de la muerte sobre los que ya la habian sufrido, y los gritos, los ayes, las lágrimas, los gemidos, las carreras, las caídas, el eco del cañón, el estallido del sable, el silbido del plomo, todo era espantoso, todo horrible, todo y de todos modos solo presentaba la comparación de aquel día que ha de presagiar la consumación de los siglos (DEL MONTE Y TEJADA, 1953, p. 244)

Convém assinalar a estrutura das representações sobre a qual são construídas as fronteiras entre a identidade dominicana e haitiana. Os valores do povo dominicano, apontados por Arredondo y Pichardo, estão em contínua oposição aos 
valores atribuídos aos haitianos. Assim, honestidade se opõe à covardia, civilização à barbárie, antropofagia a pudor, ferocidade à fragilidade etc.

É interessante analisar também o lugar da mulher branca criolla ${ }^{16}$ nas ações dos negros haitianos, pois esse tema aparece mais de uma vez nos relatos recolhidos por Marrero. Por exemplo, quando o autor retrata a ação de Dessalines frente às mulheres brancas do Haiti e de Santiago (República Dominicana) reforça a ausência de sentimentos cristãos, como compaixão e piedade. Em conjunto com as mulheres, os enfermos, as crianças e os padres são percebidos como suas vítimas prediletas. O seguinte trecho, descrito por Marrero, retrata a ação de Dessalines e sua tropa, ao capitularem, meses após sua invasão a Santo Domingo, ao Cabo Haitiano. Neste relato, também está presente a violência sexual dos soldados haitianos:

Los ancianos o aquellos que estorbaban la marcha por su estado de debilidad, eran asesinados, y cuando la caravana llegó al río de Esperanza, los apetitos de los negros se desfogaron sobre las pocas niñas que aún no habían sido violadas, sin tomar en cuenta la tierna edad de muchas de ellas (MARRERO ARISTY' 1957, p. 233).

A partir de um conjunto de oposições binárias, o pensamento social dominicano se fundamenta no antihaitianismo. Mediante o uso comparativo da história entre os dois povos, pares de dicotomias puderam ser retrabalhados, de modo a consolidar os haitianos como alteridades elementares aos dominicanos. A análise da trajetória de Jacques Dessalines, por parte de Marrero, caracteriza a natureza dessa oposição binária, respaldada por inúmeras fontes bibliográficas, dentre as quais, as de origem norte-americana:

Todos los autores que hemos leído concuerdan en que la ferocidad infrahumana de Dessalines superaba a la de todos sus compañeros, que en muchos casos, no es poco decir.

Las atrocidades de este negro ignorante comenzaron cuando mató a su propio amo, otro negro libre, cuyo nombre se apropió. Luego, al servicio de Biassou, cometió los más horrendos crímenes, entre ellos el degüelo de 300 blancos, casi todos mujeres, niños y ancianos, cuyas cabezas cortó y colocó en igual número de estacas a guisa de adorno, para darle así la bienvenida a su jefe que estaba ausente del campamento.

\footnotetext{
${ }^{16} \mathrm{Na}$ rede de significados dominicana, criollo significa nacional ou filho da terra, não possuindo qualquer relação com o plano biológico.
} 
Como General, Dessalines hacía degollar con frecuencia a sus soldados heridos, enfermos o cansados, muchas veces por centenares, para que no le estorbaran.

Como el propósito de exterminar a los blancos y a los mulatos siempre fuera su principal preocupación, hizo matanzas en masa de unos y otros, llenando de pavor al género humano.

Al servicio de Toussaint, redujo a los negros a una condición semejante a la esclavitud para hacerlos trabajar, actitud que fue acentuada cuando ejerció él mismo el gobierno.

Aunque algunos pretenden que nació en Haití, Del Monte y Tejada, que vivió en aquellos trágicos tiempos, afirma que Dessalines "conservaba toda la ferocidad y barbarie de la tierra africana en que había nacido; el sentimiento que lo dominaba era la venganza", y descollaba "entre los mismos negros como el mas cruel y sanguinario de todos" [...] (DEL MONTE Y TEJADA, 1953, p. 246).

El escritor norteamericano James G. Leyburn, profesor de la Universidad de Yale, cuya obra El Pueblo Haitiano tenemos a manos en el momento de escribir esta nota, y quien ha estudiado las cuestiones atinentes a la organización social de Haití desapasionadamente, expresa sobre Dessalines el siguiente juicio: "La exterminación de todos los blancos que quedaban en el territorio, fue una de las primeras tareas que se impuso. Con una promesa de clemencia, hizo salir de sus esconderijos a varios centenares de incautos franceses, e hizo con ellos, a sangre fría, una espantosa carnicería. Su campaña de extirpación fue metódica y total. Tratar de indagar las causas psicológicas de esta violencia, es desechar los hechos por la hipótesis: puede haber sido pura y simplemente el deseo de vengarse de los franceses, puede haber sido por deleitarse sádicamente" [...] (DEL MONTE Y TEJADA, 1953, p. 47).

El también norteamericano Sumner Welles, en su libro La Viña de Naboth, dice lo siguiente: "Dessalines había nacido en selvas del África occidental y fue traído a la colonia francesa cuando estaba en su adolescencia. Sin duda el ambiente salvaje en que pasó los primeros años de su vida, fue causa de su ignorancia impenetrable, de su crueldad horripilante $y$ de la burda superstición que siempre lo dominó; pero sólo la depravación congénita puede explicar la inapagable sed de sangre que dio siniestra notoriedad a su nombre por más de una centuria. No había horror de perversión sanguinaria tortura que no inventara su cerebro; desde el primer día de su participación en la insurrección hasta la fecha de su muerte a manos de sus congéneres en las afueras de Port-au-Prince, su 
carrera fue la de un grosero carnicero de víctimas humanas (DEL MONTE Y TEJADA, 1953, p. 44) ${ }^{17}$.

De acordo com a caracterização proposta por estes autores, a identidade haitiana encontra uma relação lógica com a África e a ideia de pureza que a inspira supõe a correlação entre ignorância, superstição, ferocidade, barbárie, subumanidade, depravação congênita, horror, crueldade e sangue.

O ponto principal de análise dessas ocupações haitianas em Santo Domingo é a elucidação, por parte da literatura dominicana selecionada, da oposição do conjunto de valores que informam a identidade dominicana e haitiana. Marrero prossegue na caracterização de valores dos dois povos, tomando como inspiração, as ocupações de 1801 e 1805:

Mientras Toussaint y su pueblo, e incluso sus subordinados militares, con las contadas excepciones de unos pocos que habían recibido educación en Francia, emergían de una noche de ignorancia, odio y brutalidad, en la que los peores instintos del hombre primitivo no habían sido domeñados, sino más bien exacerbados, en la parte española de la isla iban a cumplirse tres siglos que los naturales del país nacidos y criados dentro de los elevados principios de la Iglesia Católica - recibían educación universitaria ${ }^{18}$ y poseían una clase capacitada para desempeñar, como ocurría en efecto, los cargos públicos - civiles y militares - de la colonia, siendo cosa frecuente en el Clero español-dominicano, la presencia de sacerdotes de color que ejercían su ministerio sin discriminación alguna.

De ahí que, nada causase tanta extrañeza y fuese generalmente ofensivo, para la casi totalidad de la gente de color del Santo Domingo español, e incluso para los mismos esclavos, como el hecho de que los africanos de la parte occidental de la isla, cuyas suspicacias y violencias contrastaban con los hábitos sociales de los negros y mestizos españoles, trataran de erigirse, sólo por el imperio de la fuerza, en sus "protectores" $y$ "libertadores"; y aunque es innegable que los usurpadores occidentales hallaron algunos adeptos entre los esclavos de reciente introducción en la isla en uno que otro ingenio, o

\footnotetext{
${ }^{17}$ Cf. MARRERO ARISTY, Ramón. República Dominicana: origen y destino del pueblo cristiano más antiguo de la América. Ciudad Trujillo: Del Caribe, 1957. p. 230-235.

${ }^{18}$ Nota do autor: Ver el capítulo de esta obra La Iglesia Colonial y la cultura en el siglo XVI, en el cual se describe el nacimiento y el desarrollo de la enseñanza universitaria en Santo Domingo, antes de que hubiesen universidades en otros países de América.
} 
entre algún que otro mestizo, o negro español [como también ocurrió entre los blancos] que por miedo o conveniencia se plegara a sus requerimientos, considerando que de allí en adelante el país no volvería a recuperar su original fisonomía social y política, no es menos cierto que tales hechos aislados, $y$ en ninguna forma expresivos del sentir de la población dominicana de origen hispano-africano o africano, no fueron más que las excepciones que confirmaron la regla. (MARRERO ARISTY, 1957, p. 206).

Nessa análise de Marrero, é possível perceber como o imaginário dominicano distingue os vários tipos de negros, pois não afirma que a raça possua uma essência invariável, cuja cultura seria um mero acessório, mas distingue os negros espanhóis dos franceses englobando-os como mezclados, indicando que a mezcla não possui qualquer referência ao plano biológico. De acordo com Marrero:

El negro y el mestizo dominicanos, sin que en ello tuvieran primacía el más leve o absurdo prejuicio racial, se consideraban justamente españoles, fuese mucha, poca o ninguna la sangre hispana que corriese por sus venas, por el hecho principal de haber nacido españoles $y$ de haber asimilado la lengua, la religión y las costumbres de España; y este concepto no podrían trastornarlo Toussaint y sus sucesores ni aún empleando la fuerza, razón que ha hecho posible la indestructible diferenciación de los pueblos que ocupan la isla hasta los días presentes, en que el afianzamiento de los valores hispanos que integran el espíritu dominicano constituye una fuerza irreductible y tan perdurable como el mismo pueblo, sea cual fuere el color de la piel o el origen social del individuo. ¡Grandeza inigualable del alma genitora de España, generosa y eterna, como la de ninguna otra nación que haya sido madre de pueblos! (MARRERO ARISTY, 1957, p. 206).

A ocupação de 1822 configurou-se na ocupação mais duradoura. A definição dos valores relativos ao povo dominicano tornou-se, nesse momento, quase uma necessidade moral, pois abundavam as evidências históricas no sentido de conceber este povo como débil e inferior ao haitiano. Marrero descreve essa ocupação como mais uma humilhação à soberania do povo dominicano:

El acto de subyugación de la antigua parte española de la isla de Santo Domingo por los ejércitos del caudillo haitiano Jean Pierre Boyer, sumió a los dominicanos en la mayor vergüenza y en la desesperación absoluta. El terrible impacto que tal acontecimiento produjo en el alma nacional, fué de consecuencias verdaderamente catastróficas para la evolución 
normal de la sociedad hispánica que hasta ese momento había desenvuelto su existencia en la colonia primogénita de España en el Nuevo Mundo

Los haitianos transportaron a Santo Domingo todos sus odios $y$ suspicacias de orden racial, tratando, por todos los medios, de borrar la fisonomía espiritual, cultural y racial del pueblo dominicano.

Los primeros actos del gobierno de Boyer, además de suprimir en la práctica todas las libertades civiles, de desatar una rapaz campaña de confiscación de las propiedades de las familias que se ausentaban del país en busca de ambientes más respirables, se caracterizaron por su agresión a la cultura y por su afán de ennegrecer a la población dominicana”. (MARRERO ARISTY, 1957, p. 268-269).

O significado dessa ocupação haitiana, baseada no fomento à imigração de negros norte-americanos rumo à parte espanhola da ilha, reforçou a rivalidade entre as identidades nacionais.

El presidente Jean P. Boyer, aprovechó la circunstancia para asestar una puñalada trapera a la débil nación que hacía presencia entre la familia de pueblos libres de América, poniendo en práctica el principio proclamado por Toussaint de que la isla era una e indivisible, y haciendo buena la afirmación constitucional dictada por Dessalines, según la cual la República de Haití no tenía más límites que aquellos establecidos por la naturaleza, o sea el mar; lo cual arrojó como resultado inmediato la invasión de la parte española, con fuerzas armadas, poderosísimas, a las que no pudieron oponérseles las escasas compañías que había en el país, cuya población escasamente llegaba a sesenta mil almas diseminadas en todo el territorio. (MARRERO ARISTY, 1957, p. 267).

A Independência dominicana, conquistada em 27 de fevereiro de 1844, foi liderada pelo grupo conhecido como Los Trinitarios, fundado em 16 de julho de 1838. Juan Pablo Duarte (1813-1876), considerado o "Padre de la Patria" foi um dos principais líderes desse movimento junto com Francisco Del Rosário Sánchez (1817-1861) e Matias Ramón Mella (1816-1864). Entretanto, dezesseis anos após, a República Dominicana solicita a re-anexação à Espanha. Essa ação foi comandada pelos fazendeiros pecuaristas conhecidos como hateros. Seus objetivos entraram em choque com as convicções do movimento trinitário, pois os hateros argumentavam que o país seria incapaz de se autogovernar e a anexação a uma potência 
estrangeira seria uma forma de evitar uma nova ocupação haitiana; e, em 1861 o país foi anexado à Espanha.

Após a anexação, houve o surgimento de um amplo movimento social armado, liderado pelo general Gregório Luperón com o objetivo de restaurar a Independência. Tal fase ficou conhecida como Restauración. Logo, a Guerra de Restauración teve seu início em 1863 e dois anos mais tarde encontraria seu fim, mediante a expulsão das tropas espanholas. Alguns historiadores dominicanos definem o período compreendido entre 1861 até o início do século XX como a fase de anexionismo, pois havia uma espécie de insegurança nacional frente à ideia de independência e do autogoverno.

[...] el peligro de que la Patria sucumbiera, sometida a un poder extranjero, no se limita a la anexación a España en 1861; posteriormente se producirían otros intentos. Este anexionismo conoce, por lo menos, dos etapas perfectamente diferenciables. La primera transcurre desde principios de siglo, hasta mediados de la década de los sesenta del siglo XIX, es decir, hasta la Guerra de Restauración (1863-1865), y estuvo orientada fundamentalmente hacia metrópolis europeas. La segunda etapa se desarrolla en las últimas tres décadas del siglo XIX, y un cambio se orientó hacia la emergente potencia de Estados Unidos. (Texto extraído do site www.historiadominicana.do).

Motivado pela corrente de anexionismos, Gregório Luperón (1839-1897) escreveu inúmeras notas autobiográficas, publicadas em periódicos diversos, entre 1869 e 1888. Sobre a luta dos dominicanos frente à ocupação haitiana, Luperón coloca que:

La lucha que sostuvo el pueblo dominicano contra Haití no fue una guerra vulgar. El pueblo dominicano defendía más que su independencia; defendía su idioma, la honra de sus familias, la libertad de su comercio, la moralidad del matrimonio, el odio a la poligamia, mejor destino para su raza, mejor suerte para su trabajo, la escuela para sus hijos, el respeto a la religión de sus antepasados, la seguridad individual y de la propiedad y la facultad de poder viajar al extranjero. Era la lucha solemne de costumbres y de principios diametralmente opuestos, de la barbarie contra la civilización, de la luz contra las tinieblas, del bien contra el mal. Para el pueblo dominicano era una cuestión vital, porque no se trataba de exterminar ejércitos, sino de rechazar para siempre los caprichos feroces de un pueblo despótico, para colocarse entre las naciones civilizadas, perfeccionando su progreso y afianzando sus derechos. (CHEZ CHECO, 1997, p. 110). 
O pensamento de Luperón coincide com as percepções de inúmeros historiadores e políticos de seu tempo. A Independência Dominicana reforçou a ideia, segundo a qual, odiar um haitiano representa uma demonstração de civismo e patriotismo. Luperón expressa essa filosofia, quando proclama o seguinte discurso aos portoplatenhos ${ }^{19}$, por ocasião do apoio de membros desta comunidade a um grupo de haitianos refugiados:

¿Sabéis quién protege a la facción? Haití, Haití nuestro enemigo común, que nunca prescindirá de hacer todo el mal posible, porque nunca olvidará que mil veces lo habéis humillado! Haití, el que ordenó el degüelo de vuestros antepasados en Moca; el que profanó nuestros templos; el que pretendió veinte años vuestro territorio, y a quien veinte años se lo disputasteis palmo a palmo, humillándolo siempre! (LUPERÓN apud CHEZ CHECO, 1997, p. 111).

A fase do anexionismo representou não só a disputa entre dois políticos antagônicos, como também a fragilidade da identidade nacional. $\mathrm{O}$ resgate do valor do povo dominicano, outrora anunciado por Saint-Méry, viria no governo de Trujillo. Essa fase é considerada de intenso nacionalismo, dada as ações propostas por esse governante, no sentido de reconstrução da identidade dominicana. O período de anexionismo, caracterizado por instabilidades, invasões e ocupações pode ser expresso pelo seguinte verso do Padre Vasquez (apud MARRERO ARISTY,1957, p. 227) ${ }^{20}$ :
Ayer español nací
a la tarde fui francés,
a la noche etíope fui,
hoy dicen que soy inglés,
¡No sé que será de mí!

Luperón coloca que o período de Restauración (1863-1865) contou com a apatia dos dominicanos frente à sua sorte e destino e observa:

! Triste y mísera condición del pueblo dominicano! Su corta vida
política es fecundísima en errores. Su indiferencia y su ingratitud
por sus libertadores, ha sido para los tiranos un poderoso auxiliar
para realizar espantosas traiciones y consumar crímenes horribles.
(LUPERÓN apud CHEZ CHECO, 1997, p. 268).

\footnotetext{
${ }^{19}$ Habitantes da província de Puerto Plata, no norte da República Dominicana.

${ }^{20}$ Padre Vazquez escreve este verso em referência à ocupação Haitiana de 1805.
} 
$\mathrm{Na}$ era Trujillo, as ações políticas convergiram no sentido de reafirmar o valor da mezcla na identidade dominicana. Essa ação nacional envolveu o extermínio físico $^{21}$ dos haitianos presentes na República Dominicana.

\section{Negros no Haiti}

A partir do início do século XX, centenas de trabalhadores rurais haitianos começam a ser contratados ${ }^{22}$, por empresas dominicanas privadas, para o plantio de cana-de-açúcar nos Bateys ${ }^{23}$. A presença desses haitianos na República Dominicana suscitará, nas percepções de alguns políticos e intelectuais dominicanos, a ideia de invasão pacífica, de acordo com a qual, o governo haitiano usaria estrategicamente esses trabalhadores, com o objetivo de reconquistar a ilha. Silié encontra na história as possíveis explicações para os conflitos identitários entre dominicanos e haitianos:

${ }^{21}$ Inúmeros são os autores que se ocuparam de relatar o massacre realizado por Trujillo e seus soldados em 1937, na província fronteiriça de Dajabón, República Dominicana Dentre eles se destacam: DANTICAT, Edwidge. Cosecha de Huesos. Barcelona: Lúmen, 2000; CAMBEIRA, Alan Belén. Historical and cultural connections: la République d'Haiti and la República Dominicana. In: CAMBEIRA, Alan Belén. The Dominican Republic in historical and cultural perspective. New York: M. E. Sharpe Publishers, 1997; SILIÉ, Rubén; INOA, Orlando; ANTONIN, Arnold (Ed.). La República Dominicana y Haití frente al futuro. Santo Domingo: Ediciones FLACSO/Programa República Dominicana, 1998.

${ }^{22} \mathrm{Tal}$ contratação deve-se a inúmeros fatores. A literatura sobre este tema está dividida, a partir de duas correntes de pensamento. Uma analisa a imigração, desde o ponto de vista de um modelo genérico. Outra, incorpora variáveis locais para esta análise. Há autores que argumentam que a contratação de mão-de-obra haitiana restringe-se a razões meramente mercadológicas. Outros observam que, aliada à condição de miséria presente no Haiti, que força a emigração do trabalho, existe certo revanchismo histórico entre dominicanos e haitianos que proporciona, aos primeiros, colocarem em prática, instrumentos de inferiorização, ao qual seu povo fora submetido na ocasião das ocupações mencionadas. Cf. SILIÉ, Rubén; INOA, Orlando; ANTONIN, Arnold (Ed.). La República Dominicana y Haití frente al futuro. Santo Domingo: Ediciones FLACSO-Programa República Dominicana, 1998; SILIÉ, Rubén; SEGURA, Carlos; DORE CABRAL, Carlos (Ed.). La nueva inmigración haitiana. Santo Domingo: Ediciones FLACSO-Programa República Dominicana, 2002; HOETINK, Harry. Santo Domingo y El Caribe. República Dominicana: Fundación Cultural Dominicana, 1994.

${ }^{23}$ Batey é uma designação amplamente conhecida na República Dominicana. Trata-se de uma área dedicada tradicionalmente ao plantio de cana-de-açúcar. Como a maior parte da mão-de-obra recrutada para este tipo de trabalho é de origem haitiana, o Batey simboliza o lugar social e geográfico dos haitianos na sociedade dominicana. 
Desde principios de este siglo, la República Dominicana ha mantenido una presencia significativa de braceros haitianos que vienen a trabajar al corte de la caña [...]

En 1934, antes de experimentarse el tránsito de las empresas azucareras norteamericanas a manos de Trujillo, este último propició un incidente donde perdieron la vida más de cinco mil haitianos [...] Uno de los principales argumentos empleados ideológicamente por el gobierno para justificar tal acción, fue el hecho de que los otrora dominadores [...] aún pretendían reiterar la unificación del territorio, esta vez por la vía de la invasión pacífica, que en su momento permitiría al Estado haitiano replantear la consigna de que "La isla es una e indivisible".

Unido a este argumento, se divulgó la tesis de que la identidad cultural del pueblo dominicano se encontraba amenazada [...]. (SILIÉ; INOA; ANTONIN, 1998, p. 3).

Dessa forma, o locus privilegiado de ratificação do nacionalismo dominicano será, na era Trujillo, insistentemente representado através do limite entre as duas fronteiras. O chamado processo de dominicanização da fronteira, implementado por esse Chefe de Estado, fez ressurgir ressentimentos históricos, expressos à base de sangue, conforme assinala Silié.

Cambeira retrata a passagem do nome do Rio Dajabón, que separa a província de Dajabón (República Dominicana) de Ouanaminthe (Haiti) para "Rio Massacre", seu nome atual. No leito desse rio foram atirados os corpos de milhares de trabalhadores rurais haitianos. Tal massacre foi acionado com o intuito de frear a chamada "invasão pacífica" de trabalhadores rurais haitianos rumo à República Dominicana. Vejamos o discurso de Trujillo poucos meses antes de ordenar o extermínio desses haitianos:

Los haitianos. Su presencia en nuestro territorio no puede más deteriorar las condiciones de vida de nuestros nacionales. Esa ocupación de los haitianos de las tierras fronterizas no debía continuar. Está ordenado que todos los haitianos que hubiera en el país fuesen exterminados. (CAMBEIRA, 1997, p. 184).

“Americano de Samaná" e também perseguido na era da dominicanização, Cambeira descreve a estratégia utilizada pelos militares dominicanos na fronteira Dajabón - Ounaminthe. Um dos sinais diacríticos utilizados pelos soldados dominicanos na região de fronteira para identificar um haitiano era a língua. 
Socializados na língua kreyòl, os haitianos teriam dificuldades em pronunciar o " $\mathrm{r}$ ” e o “j”, fonemas importantes na identificação do idioma castelhano. A percepção dessa dificuldade era motivo suficiente para o consequente assassinato. É possível dizer que o limite da oposição binária entre a identidade dominicana e haitiana oculta o entre - lugar no qual não um dominicano pode ser confundido com um haitiano e vice-versa. Daí a necessidade de eliminação física da diferença, pois isso não é possível no imaginário.

A oposição entre a identidade dominicana e haitiana pode ser pensada como perfeita, já que do ponto de vista da literatura selecionada, não existem categorias do entendimento capazes de aproximar os dois povos, pois o ser dominicano constitui-se em uma negativa de tudo aquilo que representa o haitiano cuja anterioridade da negritude à cultura o distingue do povo dominicano.

\section{República Dominicana: la construcción del pueblo criollo}

\section{Resumen}

Este artículo investiga, a traves del pensamiento social dominicano, los límites de su nacionalismo lo cual se opone sistematicamente al nacionalismo haitiano, vertiéndose en una perfecta alteridad que aún así no consigue ocultar el princípio de transitabilidad existente en la constitución de las identidades nacionales opostas. Sin embargo, será a partir del tránsito contínuo hacia dentro de la identidad haitiana estereotipada que el nacionalismo dominicano va a construyr sus pilares principales, que parece perder su sentido si la oposición no se reproduce continuamente por el pensamiento social y la historiografía dominicana. Algunos hechos históricos son muy importantes para alimentar el nacionalismo dominicano que se convierte en antihaitianismo. Son ellos: las invasiones de Haití en Santo Domingo en 1801, 1804 y 1822 (el más largo). El hecho de que los dominicanos han estado dominados por una nación que era en sí misma el resultado de una insurrección de esclavos dio lugar a una gran parte del pensamiento social dominicano, a un rechazo que no se limita a la gente haitiana, pero la idea de negritud, la religión y las culturas de origen africana. Palabras-clave: Antihaitianismo. Pensamiento social dominicano. Nacionalismo Dominicano. Invasiones Haitianas. 


\section{Referências}

AAQQUIIKLĖZINE, Jènelis. Yon Koutje sou Savanèt. Bon Nouvè, Port au Prince, n. 358, 1999.

ANDERSON, Benedict. Nação e consciência nacional. São Paulo: Ática, 1989. Tradução do original Imagined communities: reflections on the origin and spread of nationalism.

ANDÚJAR, Carlos P. De cultura y sociedad. Santo Domingo: Manatí, 2001.

ANDÚJAR, Carlos P. Identidad cultural y religiosidad popula. Santo Domingo: Cole, 1999.

APPIAH, Kwame Anthony. Na casa de meu pai: a África na filosofia da cultura. Rio de Janeiro: Contraponto, 1997.

ARREDONDO Y PICHARDO, Gaspar. Memoria de mi salida de la Isla de Santo Domingo el 28 de abril de 1805. In: DEMORIZI, Emilio Rodríguez (Ed.). Invasiones haitianas de 1801, 1805 y 1822. Ciudad Trujillo: Academia Dominicana de la Historia, 1955.

AZEVEDO, Célia M. de. Onda negra, medo branco: o negro no imaginário das elites: século XIX. Rio de Janeiro: Paz e Terra, 1987.

BALAGUER, Joaquín. La Isla al revés: Haití y el destino dominicano. Santo Domingo: Librería Dominicano, 1984.

BAUD, Michael et al. Etnicidad como estrategia en América Latina y el Carib. Quito: Abya-Yala, 1996.

BHABHA, Homi. O local da cultura. Belo Horizonte: UFMG, 2001.

BOERSNER, Demetrio. Relaciones internacionales de América Latina: breve historia. [S.1.]: Nueva Sociedad, 1996.

CAMBEIRA, Alan Belén. Historical and cultural connections: la République d'Haiti and la República Dominicana. In: CAMBEIRA, Alan Belén. The Dominican Republic in historical and cultural perspective. New York: M. E. Sharpe, 1997.

CARUSO, Raimundo C. A invasão brasileira de 1965 e a Guerra de Santo Domingo. São Paulo: Ícone, 1988. 
CÉSAIRE, Aimé. Toussaint Louverture. La Habana: Instituto del Libro, 1967.

CHANLATTE, Antonio. Al gobierno Francés y a todos los amigos de la soberanía nacional y del orden. RODRÍGUEZ DEMORIZI, Emilio (Ed.). La era de Francia en Santo Domingo. Ciudad Trujillo: Academia Dominicana de la Historia, 1955.

CHEVANNES, Barry. Rastafari and other african-caribbean worldviews. New Brunswick, New Jersey: Rutgers University Press, 1998.

CHEZ CHECO, José. Ideário de Luperón (1839-1897). Santo Domingo: Taller, 1997.

DANTICAT, Edwidge. Cosecha de Huesos. Barcelona: Lúmen, 2000.

DEL MONTE Y TEJADA, Antonio. Historia de Santo Domingo. Ciudad Trujillo: Impresora Dominicana, 1953.

DELAFOSSE, Lemonier. Segunda campaña de Santo Domingo: guerra DomínicoFrancesa de 1808. Santiago: El Diario, 1946.

DESPRADEL I BATISTA, Guido. Raíces de nuestro espíritu: un ensayo. Santo Domingo: Renovación, 1971.

DEWOLIS, Moyiz. Kouman ou ka al Beladè? Bon Nouvèl, Port au Prince, n. 365, 2000.

DIEDERICH, Bernard e AL BURT. Papa Doc et les Tontons Macoutes. Port-au-Prince: Imprimerie Henri Deschamps, 1986.

ETIENNE, Frank. Pèlin tèt. Port-au-Prince: Editions du Soleil, 1978.

GARCÍA, José Gabriel. Compendio de la historia de Santo Domingo. Santo Domingo: Imprenta de García Hermanos, 1892.

GONZALES, Nancy. Patterns of dominican ethnicity. In: BENNETT, John W. (Org.). The new ethnicity: perspectives from ethnology. United States of America: West Publishing Co, 1975.

HEIDHEM, Harald. When cultural identity is a stigma. In: BARTH, Fredrik (Org.). Ethnic groups and boundaries: the social organization of culture difference. BergenOslo: Universitets Forlaget, 1969.

HENRY, Paget. Caliban's reason: introducing afro-caribbeann philosophy. Londres/ Nova Iorque: Routledge, 2000. 
HOBSBAWN, Eric. Etnia e nacionalismo na Europa de hoje. In: BALAKRISHNAN, Gopal (Org.). Um mapa da questão nacional. Rio de Janeiro: Contraponto, 2000.

HOBSBAWN, Eric. Nações e nacionalismos desde 1780. Rio de Janeiro: Paz e Terra, 1991.

HOETINK, Harry. Caribbean race relations: a study of two variants. London: Oxford University Press, 1967.

HOETINK, Harry. Santo Domingo y el Caribe: ensayos sobre historia y sociedad. Santo Domingo: Fundación Cultural Dominicana, 1994.

HOFFMAN, Leon-François. Slavery and race in haitian letters. Caribbean Review, [S.1.], v. 9, n.2, p. 28-32, 1980.

KNIGHT, Franklin W. Race, ethnicity, and class: forging the plural society in Latin America and the Caribbean. Waco, Texas: Baylor University, 1996. (The seventeenth Charles Edmondson historical lectures).

LUPERÓN, Gregorio. Proclama los puertoplateños, Puerto Plata, 21 de noviembre de 1867. In: CHEZ CHECO, José. Ideário de Luperón (1839-1897). Santo Domingo: Taller, 1997.

MANIGAT, Mirlande. Los derechos humanos en la Constitución Haitiana de 1987. In: TEJEDA, Eddy (Ed.). El derecho a una vida digna. Santo Domingo: FLACSO, 2002.

MARRERO ARISTY, Ramón. República Dominicana: origen y destino del pueblo cristiano más antiguo de la América. Ciudad Trujillo: Del Caribe, 1957.

MIRES, Fernando. La rebelión permanente. México: Siglo XXI Editores, 1988.

MOYA PONS, Frank. Historia colonial de Santo Domingo. Santiago, República Dominicana: Universidad Católica Madre y Maestra, 1974.

MURRAY, Gerald F. Bon-Dieu e os ritos de passagem no Haiti rural: determinantes estruturais da teologia e dos rituais pós-coloniais. Estudos Afro-Asiáticos, [S.l.], n. 19, 1990.

NICHOLLS, David. From dessalines to Duvalier: race, colour and national independende in Haiti, New Brunwick, NJ: Rutgers University Press, 2000. 
PIERRE-CHARLES, Gérard. El Caribe contemporâneo. México: Siglo XXI Editores, 1981.

PRICE-MARS, Jean. Así habló el ti. Santo Domingo: Manatí, 2000. Tradução do original Ainsi parla loncle.

RAMIREZ, Nelson. Las migraciones internas en República Dominicana. Santo Domingo: IEPD, 1993.

RODRÍGUEZ DEMORIZI, Emilio (Ed.). Cesión de Santo Domingo a Francia. Ciudad Trujillo: Archivo General de la Nación, 1958.

RODRÍGUEZ DEMORIZI, Emilio (Ed.). Invasiones haitianas de 1801, 1805 y 1822. Ciudad Trujillo: Academia Dominicana de la Historia, 1955.

RODRÍGUEZ DEMORIZI, Emilio (Ed.). La era de Francia en Santo Domingo. Ciudad Trujillo: Academia Dominicana de la Historia, 1955.

SAINT-MÉRY, M. L. Moreau de. Descripción de la parte española de Santo Domingo. Ciudad Trujillo: Montalvo, 1944.

SÁNCHEZ VALVERDE, Antonio. Idea del valor de la Isla Española. Ciudad Trujillo: Montalvo, 1947.

SILIÉ, Rubén. Esclavege et prejuge de coleur en Republique Dominicaine. Revue Franco-Haitienne, Conjonction, [S.l.], n. 147, 1980.

SILIÉ, Rubén. Población y esclavitud en Santo Domingo, en el Siglo XVIII. Revista Investigación y Ciencia, [S.1.], ano 1, n. 1, 1986.

SILIÉ, Rubén; INOA, Orlando; ANTONIN, Arnold (Ed.). La República Dominicana y Haití frente al futuro. Santo Domingo: Ediciones FLACSO/Programa República Dominicana, 1998.

SILIÉ, Rubén; SEGURA, Carlos; DORE CABRAL, Carlos (Ed.). La nueva inmigración haitiana. Santo Domingo: Ediciones FLACSO/Programa República Dominicana, 2002.

SMITH, M.G. Pluralism, politics and ideology in the creole caribbean. New York: Research Institute for the Study of Man, 1991. (Vera Rubin Caribbean Series, n. 1).

TROUILLOT, Michel-Rolph. The caribbean region: an open frontier in anthropological theory. Annual Review of Anthropology, [S.1.], n. 21, p. 19-42, 1992. 